\title{
Proteins involved in oxidative stress in leiomyoma tissues treated with ulipristal acetate
}

\author{
BLENDI URA $^{1}$, LORENZO MONASTA ${ }^{1}$, YERALDIN CHIQUINQUIRA CASTILLO DE SPELORZI ${ }^{2}$, \\ GIORGIO ARRIGONI $^{3,4}$, CINZIA FRANCHIN ${ }^{3,4}$, STEFANIA BIFFI ${ }^{1}$, MICHELANGELO ALOISIO ${ }^{5}$, \\ BARTOLOMEA GAITA $^{2}$, DANILO LICASTRO ${ }^{6}$, EMMANOUIL ATHANASAKIS ${ }^{1}$, FEDERICA SCRIMIN $^{1}$, \\ GUGLIELMO STABILE ${ }^{1}$, FEDERICO ROMANO ${ }^{1}$, GIOVANNI DI LORENZO ${ }^{1}$ and GIUSEPPE RICCI ${ }^{1,7}$ \\ ${ }^{1}$ Institute for Maternal and Child Health-IRCCS 'Burlo Garofolo', I-34137 Trieste; ${ }^{2}$ Life Sciences Department, \\ University of Trieste, I-34128 Trieste; ${ }^{3}$ Department of Biomedical Sciences, University of Padova, I-35121 Padova; \\ ${ }^{4}$ Proteomics Center, University of Padova and Azienda Ospedaliera di Padova, I-35129 Padova; \\ ${ }^{5}$ Central RNA Laboratory, Istituto Italiano di Tecnologia, I-16163 Genova; ${ }^{6}$ ARGO Open Lab Platform \\ for Genome Sequencing, AREA Science Park, I-34149 Trieste; ${ }^{7}$ Department of Medical, \\ Surgery and Health Sciences, University of Trieste, I-34148 Trieste, Italy
}

Received March 19, 2020; Accepted September 3, 2020

DOI: $10.3892 / \mathrm{mmr} .2020 .11642$

\begin{abstract}
Uterine leiomyoma presents the highest incidence among benign tumors of the female reproductive tract. The present study compared the proteome of leiomyoma treated with ulipristal acetate with that of untreated leiomyoma to investigate protein expression patterns in relation to oxidative stress. Paired tissue samples from seven treated and untreated leiomyomas were collected and the proteome was analyzed by two-dimensional gel electrophoresis (2-DE). Western blotting was used to validate the results of 2-DE, and mass spectrometry was used to identify proteins. The tissue expression of 30 proteins was markedly affected by treatment with ulipristal acetate. Bioinformatics analysis revealed that several of the differentially expressed proteins were involved in the degradation of hydrogen peroxide and the synthesis of reactive oxygen species. The present study suggested the involvement of oxidative stress as a novel mechanism of action of ulipristal acetate. These findings require further investigations to understand the role of ulipristal acetate in the treatment of the leiomyoma.
\end{abstract}

\section{Introduction}

Uterine leiomyoma is a benign tumor that affects $70-80 \%$ of women, which is the highest incidence amongst the benign tumors of the female reproductive tract $(1,2)$. This neoplasm is

Correspondence to: Dr Blendi Ura, Institute for Maternal and Child Health-IRCCS 'Burlo Garofolo', 65/1 Via dell'Istria, I-34137 Trieste, Italy

E-mail: blendi.ura2006@burlo.trieste.it

Key words: ulipristal acetate, leiomyoma, mass spectrometry, two-dimensional electrophoresis, proteomics responsible for serious health problems (3) and is characterized by abnormal extracellular matrix (4), altered phosphoproteins (5), dysregulated chaperones (6), and alterations in the proteins involved in cell migration (7).

The management of leiomyoma is an emerging clinical issue as the symptoms, which include poliabortivity, pain, and heavy uterine bleeding (3), can severely affect women and female fertility.

For the management of symptomatic leiomyoma, surgical techniques, such as myomectomy and hysterectomy, are traditionally used (8). However, due to the high morbidity of uterine leiomyoma, there is urgent need for a more effective therapeutic approach, capable of improving the quality of life of these patients (9).

For the treatment of symptomatic leiomyoma patients there are, in addition to surgery, pharmacological therapies based on gonadotropin-releasing hormone agonists and selective progesterone receptor modulators (10), that can effectively reduce the volume of the leiomyoma (11). Among them, ulipristal acetate (UPA) is a selective progesterone receptor modulator (SPRM) used preoperatively to control leiomyoma growth (12). It controls progesterone receptor activity and leads to apoptosis of leiomyoma cells. However, the exact mechanism of action of this drug is still unknown (13). Interestingly, Maruo et al (14) reported that treating leiomyoma cell cultures with UPA induced the expression of matrix metalloproteinase MMP1 and MMP8 and decreased the expression of TIMP, while treatment of myometrium cells with UPA did not lead to protein dysregulation.

The objective of our study was to identify dysregulated proteins in leiomyoma tissue treated with UPA and in untreated leiomyoma, to gain an insight into the mechanism of action of this drug.

\section{Materials and methods}

Uterine leiomyoma samples. Seven premenopausal patients treated with ulipristal acetate and seven untreated patients who 
underwent hysterectomy for symptomatic uterine leiomyomas were enrolled. To be eligible for this study, all patients signed a written informed consent form. The median age of the patients was 42 years, with a minimum of 35 and a maximum of 48 years.

All study procedures complied with the Declaration of Helsinki and were approved by the Ethical Review Board of the Institute for Maternal and Child Health-IRCCS 'Burlo Garofolo' (Trieste, Italy).

Oncologic patients, human immunodeficiency virus (HIV), hepatitis B virus (HBV), hepatitis C virus (HCV) seropositive patients, and subjects with adenomyosis were excluded from the study. The patients were treated with UPA six months before surgery.

Tissue samples. All samples were collected from the central area of the leiomyomas, which were all benign and without atypical features. They were subserosal/intramural, with dimensions ranging from 4 to $6 \mathrm{~cm}$. The samples were stored at $-80^{\circ} \mathrm{C}$ until proteomic analysis was performed.

2-DE and image analysis. 2-DE was performed as previously described (15). Briefly, clean samples of treated and untreated leiomyoma and myometrium (200 $\mathrm{mg}$ each) were homogenized in $1.2 \mathrm{ml}$ of dissolution TUC buffer [7 $\mathrm{M}$ urea, $2 \mathrm{M}$ thiourea, 4\% CHAPS, $40 \mathrm{mM}$ Tris, $65 \mathrm{mM}$ DTT and $0.24 \%$ Bio-Lyte (3-10)] with a protease inhibitor mix (2 mM PMSF, $1 \mathrm{mM}$ benzamidine, $1 \mathrm{mM}$ EDTA, $1 \mathrm{mM} \mathrm{NaF})$. After vortex, the solutions were centrifuged at $10,000 \mathrm{x} g$ at $4^{\circ} \mathrm{C}$ for $30 \mathrm{~min}$, and the protein content of the supernatant was determined using the Bradford assay. For 2-DE analysis, $400 \mu \mathrm{g}$ of proteins from each sample (leiomyomas treated with UPA and untreated leiomyomas) were used. ReadyStrip ${ }^{\mathrm{TM}} \mathrm{pH}$ 4.0-7.0 and 3-10 NL 18-cm immobilized pH gradient (IPG) strips were rehydrated in a dissolution buffer at $50 \mathrm{~V}$ for $12 \mathrm{~h}$ at $20^{\circ} \mathrm{C}$, and isoelectric focusing (IEF) was performed in a PROTEAN IEF Cell (Bio-Rad Laboratories). After IEF, serial incubations were performed: First, the IPG strips were equilibrated for $20 \mathrm{~min}$ in an equilibration buffer [6 $\mathrm{M}$ urea, 2\% SDS, $50 \mathrm{mM}$ Tris- $\mathrm{HCl}$ (pH 8.8), 30\% glycerol and 1\% DTT] and then in equilibration buffer containing $4 \%$ iodoacetamide instead of DTT. For the second dimension, the equilibrated IPG strips were transferred to a $12 \%$ polyacrylamide gel. After electrophoresis, the gels were fixed in $40 \%$ methanol and $10 \%$ acetic acid for $1 \mathrm{~h}$, and then stained for $16 \mathrm{~h}$ with SYPRO Ruby. After SYPRO Ruby destaining, the gels were stained for $48 \mathrm{~h}$ with colloidal Coomassie Brilliant Blue. The 2-DE gels were scanned with a Molecular Imager PharosFX System. Two experimental replicates were performed for each sample. For all gels, molecular weights were determined by comparison with Precision Plus Protein Prestained Standards (Bio-Rad Laboratories, Inc.) covering a range from 10 to $250 \mathrm{kDa}$, and analyzed using the Proteomweaver 4.0 software (both from Bio-Rad Laboratories, Inc.).

Quantification of spot levels. 2-DE image analysis was performed using the Proteomweaver 4.0 software, matching all gels from seven treated and seven untreated leiomyomas. to identify quantitative differences. Fold change was calculated as the ratio between the mean $\% \mathrm{~V}$ of the treated and untreated leiomyomas. Differences were considered significant when the ratio of the mean percentage relative volume $(\% \mathrm{~V})$ $(\% \mathrm{~V}=\mathrm{V}($ single spot $) / \mathrm{V}($ total spot $))$ was \pm 1.5 -fold and satisfied the non-parametric Wilcoxon test $(\mathrm{P}<0.05)$.

Trypsin digestion and MS analysis. After excision from 2-DE gels, the spots were washed four times with $50 \mathrm{mM} \mathrm{NH}_{4} \mathrm{HCO}_{3}$ and acetonitrile (ACN; Sigma-Aldrich; Merck KGaA) and dried under vacuum in a SpeedVac system. Three microliters of $12.5 \mathrm{ng} / \mu \mathrm{l}$ sequencing grade modified trypsin (Promega Corporation) in $50 \mathrm{mM} \mathrm{NH} \mathrm{HCO}_{3}$ were added for gel spot digestion; samples were digested overnight at $37^{\circ} \mathrm{C}$. Peptide extraction was performed with three changes of extraction solution of $50 \%$ ACN/0.1\% formic acid (FA; Fluka), peptide mixtures were dried under vacuum and stored at $-20^{\circ} \mathrm{C}$ until mass spectrometry (MS) analysis.

For MS analysis, samples were dissolved in $12 \mu \mathrm{l}$ of $3 \% \mathrm{ACN} / 0.1 \% \mathrm{FA}$, and $4 \mu \mathrm{l}$ of each sample were analyzed by LC-MS/MS on an LTQ-Orbitrap XL mass spectrometer (Thermo Fisher Scientific, Inc.) coupled with a nano-HPLC Ultimate 3000 (Dionex; Thermo Fisher Scientific, Inc.). Peptides were separated in a $10 \mathrm{~cm}$ pico-frit column $(75 \mu \mathrm{m}$ ID, $15 \mu \mathrm{m}$ Tip; New Objective) packed in-house with C18 material (Aeris Peptide $3.6 \mu \mathrm{m}$ XB-C18, Phenomenex). $\mathrm{H}_{2} \mathrm{O} / \mathrm{FA} 0.1 \%$ and ACN/FA $0.1 \%$ were employed as eluents $\mathrm{A}$ and $\mathrm{B}$, respectively, and peptides were analyzed at a flow rate of $0.25 \mu \mathrm{l} / \mathrm{min}$ using a linear gradient of eluent B from 3 to $40 \%$ in $20 \mathrm{~min}$. A Data Dependent Acquisition (DDA) was used: A full scan between 300 and $1,700 \mathrm{Da}$ was performed at high resolution $(60,000)$ on the Orbitrap. The ten most intense ions were selected for CID fragmentation and acquisition of MS/MS data in low resolution in the linear ion trap.

Raw data files were analyzed with the Proteome Discoverer 1.4 software package (Dionex-Thermo Fisher Scientific, Inc.) and searched with the Mascot Search Engine (version 2.2.4, Matrix Science). Spectra were searched against the human section of the Uniprot database (version July 2018) using the following parameters: Enzyme specificity was set to trypsin with 1 missed cleavage allowed, precursor and fragment ions tolerance were $10 \mathrm{ppm}$ and $0.6 \mathrm{Da}$, respectively. Carbamidomethylcysteine and oxidation of methionine were selected as fixed and variable modifications, respectively. Proteins were considered as positive hits if at least 3 unique peptides for each protein were identified with high confidence (FDR <0.01\%).

Western blotting. Protein extracts $(50 \mu \mathrm{g})$ used for 2-DE were separated by $12 \%$ SDS-PAGE and then transferred to a nitrocellulose membrane. The membrane was blocked by treatment with 5\% dry milk in TBS-Tween 20 . After milk saturation, the membrane was incubated overnight at $4^{\circ} \mathrm{C}$ with 1:300 diluted primary rabbit polyclonal antibody against PDIA3, 1:300 diluted primary rabbit polyclonal antibody against HSPB1, 1:5,000 diluted primary rabbit polyclonal antibody against ACTG2. The membrane was washed three times in TBST for $10 \mathrm{~min}$ and then incubated for $90 \mathrm{~min}$ at $4^{\circ} \mathrm{C}$ with a horseradish peroxidase-conjugated anti-rabbit immunoglobulin $\mathrm{G}$ antibody (Sigma-Aldrich; Merck KGaA) at 1:3,000 dilution. Protein expression was visualized by chemiluminescence 


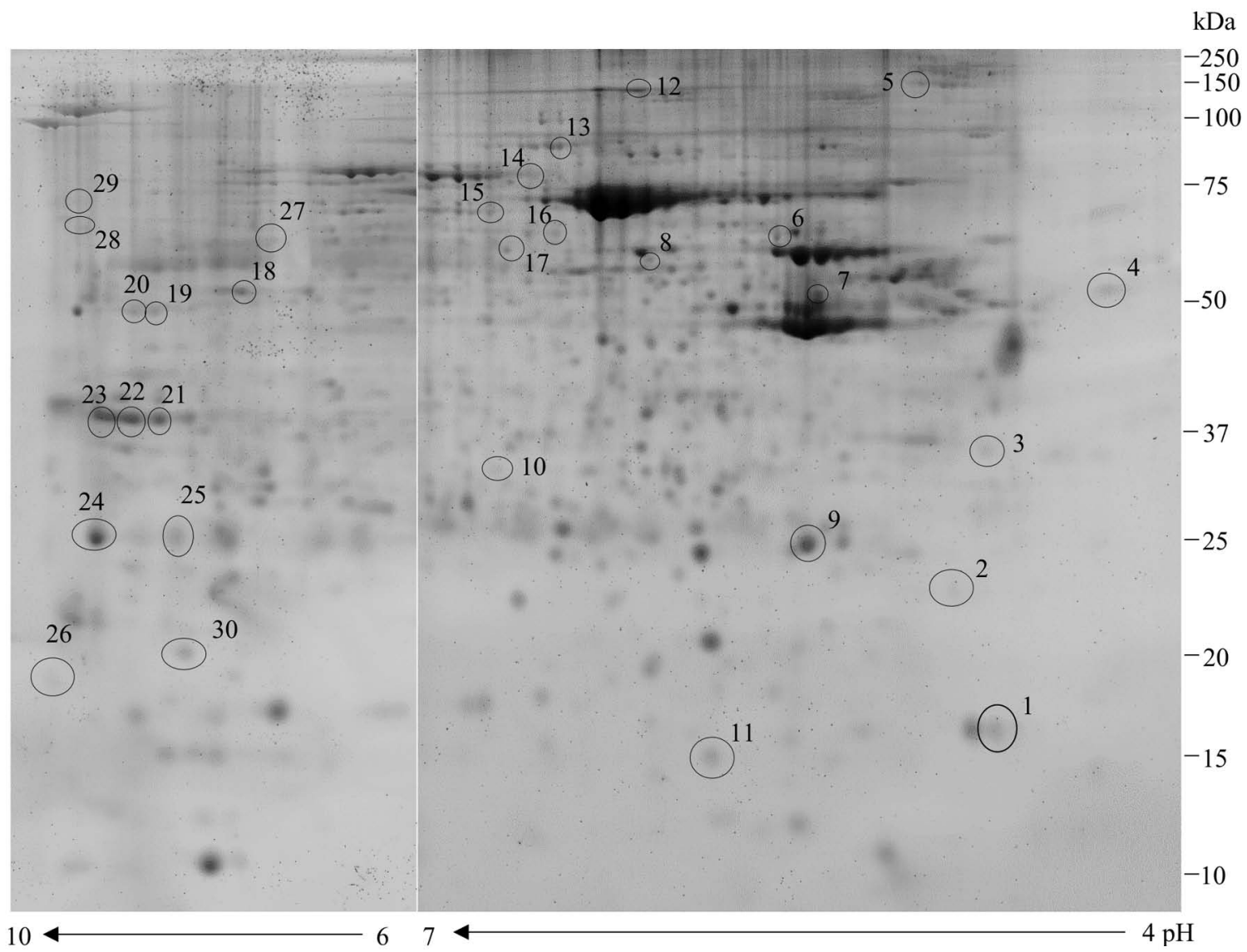

Figure 1. Master gel with the differentially abundant spots among treated and untreated leiomyoma with both pH range 4-7 and 6-10.

(SuperSignal West Pico Chemiluminescent Substrate; Thermo Fisher Scientific, Inc.), and the intensity of the signals was quantified by VersaDoc Imaging System (Bio-Rad Laboratories, Inc.). No technical replicates were performed for each sample ( 5 cases and 5 controls were analyzed). The intensities of the immunostained bands were normalized with the protein intensities measured by Red Ponceau (Sigma-Aldrich; Merck $\mathrm{KGaA}$ ) from the same blot.

Ingenuity pathway (IPA) analysis. Dysregulated proteins identified by MS in the treated and untreated leiomyomas, were analyzed by IPA (Qiagen $\mathrm{GmbH}$ ) with a P-value $<0.05$ indicating a statistically significant value. Selected genes were used to generate bio-functions. For the filter summary, only associations with high (predicted) confidence or that had been experimentally observed, were considered.

Statistical analysis. Statistical analyses were carried out with the non-parametric Wilcoxon signed-rank test for matched samples for both 2-DE and western blotting data. $\mathrm{P}<0.05$ was considered to indicate a statistically significant difference. All the analyses were conducted with Stata/IC 14.1 for Windows (StataCorp LP).

\section{Results}

Proteomic studies. In this study, we performed comparative proteomic analysis of leiomyoma tissues treated and untreated with ulipristal acetate with the aim of generating 2-DE reference maps and identifying dysregulated proteins. Gel-pairs correlation analysis highlighted an average matching efficiency of $\sim 80 \%$. Fig. 1 shows the 5,000 protein spots detected on the gel with ReadyStrip pH 4.0-7.0 and 6.0-10.0, for both types of proteomes. As reported in Table I, 13 protein spots were significantly upregulated ( $>1.5$-fold), and 17 were significantly downregulated ( $<0.6$-fold) in treated and untreated leiomyomas. Mass spectrometry analysis was applied to identify the 30 proteins modulated by the treatment, searching the MS/MS data against the human section of the UniProt database.

Western blotting study of altered proteins. In this study, we validated the downregulation of PDIA3, HSPB1, and ACTG2. Following bioinformatic analysis, we selected HSPB1, an optimal candidate due to its involvement in the inhibition of the synthesis of reactive oxygen species, and PDIA3 and ACTG2, for which antibodies are commercially available. Fig. 2 shows a quantitative comparative western blot analysis of PDIA3, HSPB1, ACTG2 expression in a cohort of five treated and five untreated leiomyoma tissue samples (previously analyzed through 2-DE). To normalize the results of our WB analysis, we determined the total protein content of each sample by Red Ponceau. The reason for this was that, according to our previous results (16) the proteins that are usually selected as encoded by housekeeping genes (i.e., $\beta$-actin, tubulin or GAPDH) are upregulated in leiomyoma and, thus, they are 
Table I. Dysregulated proteins identified by mass spectrometry in treated compared with untreated leiomyoma.

\begin{tabular}{|c|c|c|c|c|c|c|c|}
\hline $\begin{array}{l}\text { Accession } \\
\text { number }\end{array}$ & $\begin{array}{c}\text { Spot } \\
\text { number }\end{array}$ & $\begin{array}{c}\text { Protein } \\
\text { description }\end{array}$ & $\begin{array}{l}\text { Gene } \\
\text { symbol }\end{array}$ & $\begin{array}{l}\text { Molecular } \\
\text { weight, } \mathrm{kDa}\end{array}$ & $\begin{array}{l}\text { Protein } \\
\text { score }\end{array}$ & $\begin{array}{l}\text { Fold } \\
\text { change }^{\mathrm{a}}\end{array}$ & P-value \\
\hline P38919 & 17 & $\begin{array}{l}\text { Eukaryotic initiation } \\
\text { factor } 4 \mathrm{~A}-\mathrm{III}\end{array}$ & EIF4A3 & 46.8 & 117.11 & 6.60 & 0.0277 \\
\hline P17661 & 8 & Desmin & DES & 53.5 & 740.50 & 5.50 & 0.0180 \\
\hline P49903-2 & 14 & Selenide, water dikinase 1 & SEPPHS1 & 42.9 & 85.70 & 3.12 & 0.0180 \\
\hline P50990-3 & 11 & $\begin{array}{l}\text { T-complex protein } 1 \\
\text { subunit theta }\end{array}$ & CCT8 & 59.6 & 289.66 & 2.80 & 0.0180 \\
\hline P06733 & 18 & Alpha-enolase & ENO1 & 47.1 & 564.98 & 2.62 & 0.0180 \\
\hline A0A0C4DGN4 & 9 & $\begin{array}{l}\text { Zymogen granule protein } 16 \\
\text { homolog B }\end{array}$ & ZG16B & 22.7 & 395.54 & 2.56 & 0.0180 \\
\hline A6NL76 & 29 & Actin, alpha skeletal muscle & ACTA1 & 42 & 37.86 & 2.40 & 0.0273 \\
\hline P01024 & 16 & Complement C3 & $\mathrm{C} 3$ & 187.1 & $1,179.72$ & 2.39 & 0.0310 \\
\hline A0A087WWT3 & 12 & Serum albumin & ALB & 69.3 & 319.93 & 2.00 & 0.0180 \\
\hline Q86YZ3 & 21 & Hornerin & HRNR & 282.3 & 145.20 & 1.96 & 0.0277 \\
\hline P51911-2 & 28 & Isoform-2 of Calponin-1 & CNN1 & 33.1 & 140.28 & 1.74 & 0.0273 \\
\hline P30041 & 6 & Peroxiredoxin-6 & PRDX6 & 25 & 729.76 & 1.60 & 0.0277 \\
\hline P23284 & 26 & $\begin{array}{l}\text { Peptidyl-prolyl cis-trans } \\
\text { isomerase B }\end{array}$ & PPIB & 23.7 & 124.27 & 1.56 & 0.0178 \\
\hline Q01995 & 22 & Transgelin & TAGLN & 22.6 & 213.46 & 0.64 & 0.0180 \\
\hline O60814 & 2 & Histone H2B type 1-K & HIST1H2BK & 13.8 & 302.83 & 0.62 & 0.0180 \\
\hline P00441 & 3 & Superoxide dismutase $[\mathrm{Cu}-\mathrm{Zn}]$ & SOD1 & 15.9 & 288.96 & 0.60 & 0.0178 \\
\hline P51911 & 23 & Calponin-1 & CNN1 & 33.1 & 140.28 & 0.48 & 0.0180 \\
\hline Q01518-2 & 27 & $\begin{array}{l}\text { Adenylyl cyclase-associated } \\
\text { protein } 1\end{array}$ & CAP1 & 51.9 & 109.18 & 0.47 & 0.0180 \\
\hline P04792 & 5 & Heat shock protein beta-1 & HSPB1 & 22.7 & 758.06 & 0.44 & 0.0178 \\
\hline P30101 & 10 & Protein disulfide-isomerase A3 & PDIA3 & 56.7 & 425.61 & 0.41 & 0.0180 \\
\hline P63267 & 13 & $\begin{array}{l}\text { Actin, gamma-enteric } \\
\text { smooth muscle }\end{array}$ & ACTG2 & 41.8 & 233.17 & 0.39 & 0.0178 \\
\hline P02647 & 30 & Apolipoprotein A-I & APOA1 & 30.7 & $1,181.10$ & 0.38 & 0.0273 \\
\hline B0YJC4 & 4 & Vimentin & VIM & 53.6 & 339.62 & 0.36 & 0.0180 \\
\hline G3V4W0 & 7 & $\begin{array}{l}\text { Heterogeneous nuclear } \\
\text { ribonucleoproteins } \mathrm{C} 1 / \mathrm{C} 2\end{array}$ & HNRNPC & 33.6 & 387.32 & 0.30 & 0.0180 \\
\hline Q01995 & 19 & Transgelin & TAGLN & 22.6 & 343.38 & 0.30 & 0.0277 \\
\hline Q01995 & 20 & Transgelin & TAGLN & 22.6 & 608.19 & 0.26 & 0.0180 \\
\hline Q6P452 & 15 & Annexin A4 & ANXA4 & 35.8 & 299.01 & 0.26 & 0.0277 \\
\hline P69905 & 24 & Hemoglobin subunit alpha & HBA1 & 15.2 & 90.15 & 0.23 & 0.0277 \\
\hline Q5D862 & 25 & Filaggrin-2 & FLG2 & 248 & 26.81 & 0.23 & 0.0277 \\
\hline F8VPF3 & 1 & Myosin light polypeptide 6 & MYL6 & 16.9 & 205.98 & 0.03 & 0.0178 \\
\hline
\end{tabular}

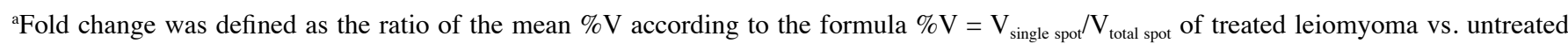
leiomyoma.

not adequate to be used as controls for normalization. Because we could not establish which proteins should be considered as housekeeping in our samples, we decided to apply a total protein content normalization method, as reported in several other publications $(17,18)$.

Functional analysis. The core analysis with IPA was performed on the proteins identified by mass spectrometry, comparing treated and untreated leiomyomas. Fig. 3 shows the networks in which these proteins are most involved, i.e. the degradation of hydrogen peroxide and the synthesis of reactive oxygen species. The regulatory network that controls the degradation of hydrogen peroxide includes three of the proteins identified: HSBA1, PRDX6, SOD1. In particular, PRDX6 and SOD1 are associated with the activation of the degradation of hydrogen peroxide, while eight other proteins participate in the network responsible for the synthesis of reactive oxygen species. Among these, TAGLN, C3, ALB, PDRX6 are involved in the 

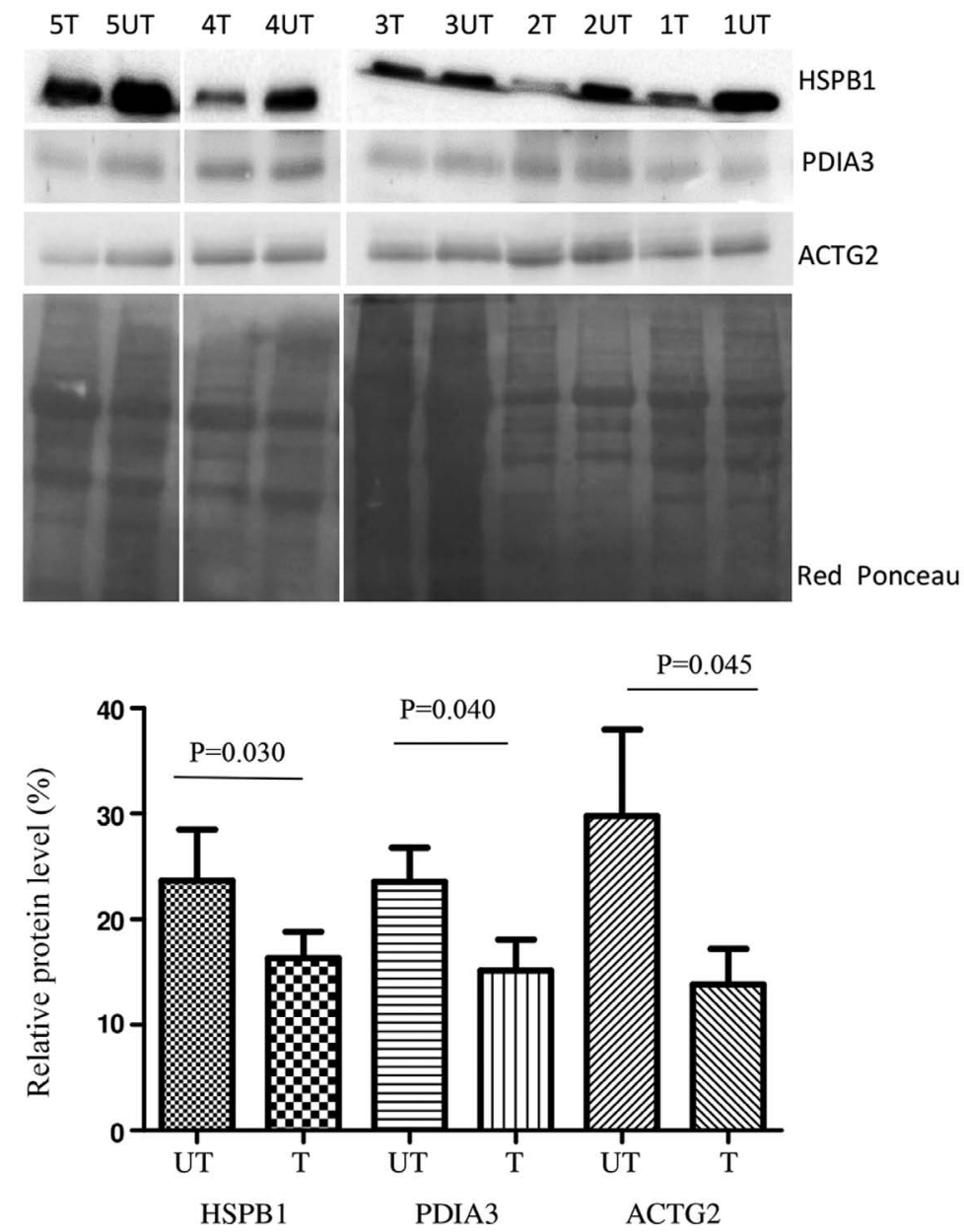

Figure 2. Western blot analysis of HSPB1, PDIA3 and ACTG2 in T and UT leiomyoma samples. The intensity of the immunostained bands was normalized against the total protein intensities measured from the same blot stained with Red Ponceau. Numbers 1-5 indicate the patients. The bar graph shows the relative expression (band density) of HSPB1, PDIA3 and ACTG2. The results are shown as a histogram $(\mathrm{P}<0.05)$ and each bar represents the mean \pm standard deviation. T, treated; UT, untreated; HSPB1, heat shock protein family B (small) member 1; PDIA3, protein disulfide isomerase family A member 3; ACTG2, actin $\gamma 2$, smooth muscle.

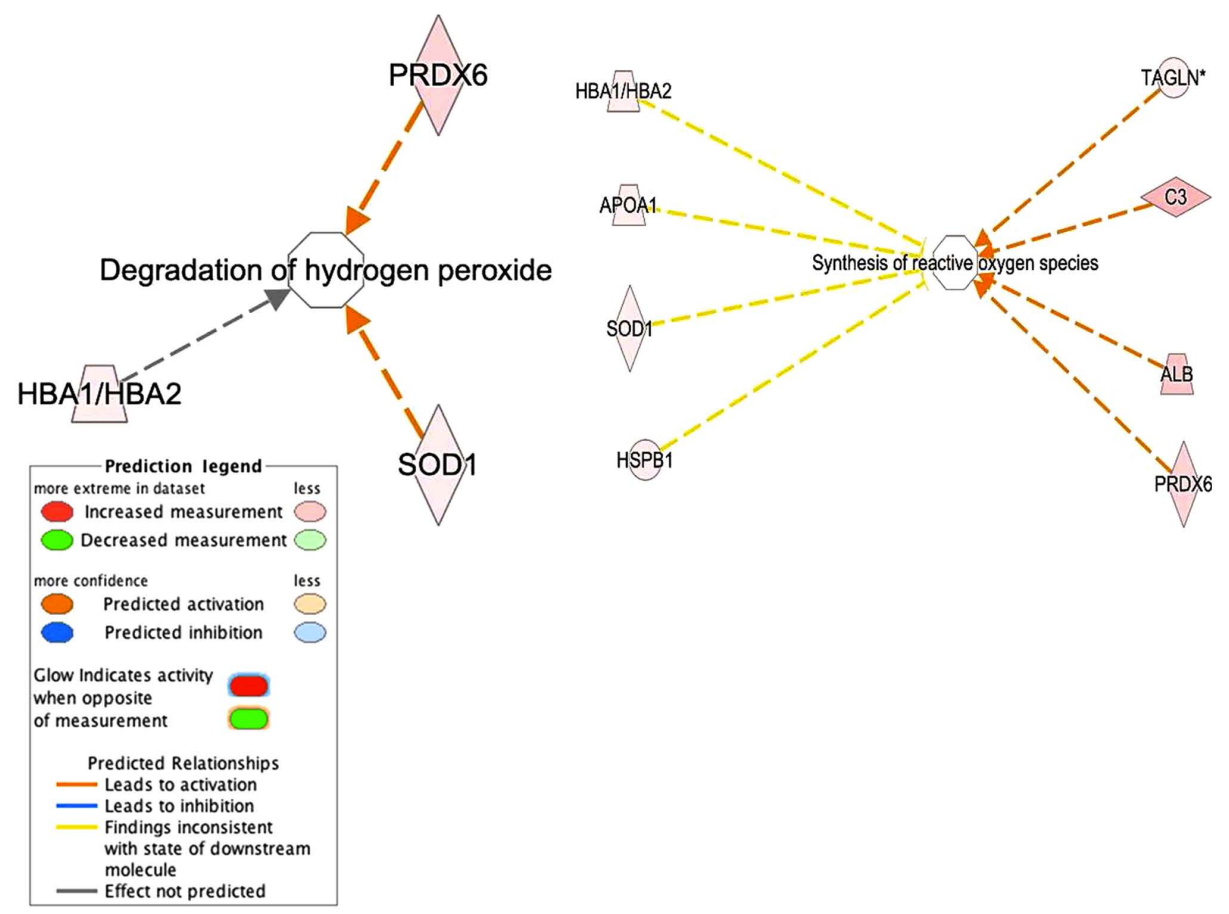

Figure 3. Network of one of the most significant bio-functions. Degradation of hydrogen peroxide and synthesis of reactive oxygen species. The network was constructed using ingenuity pathway analysis. 
activation of the synthesis of reactive oxygen species, while HBA1, APOA1, SOD1, HSPB1 are implicated in the inhibition of synthesis of reactive oxygen species. PRDX6 is linked both to the degradation of hydrogen peroxide and to the synthesis of reactive oxygen species.

\section{Discussion}

In response to the urgent need for an efficient therapeutic approach for leiomyomas, selective progesterone receptor modulators (SPRMs) might offer a valid option (19,20). This study represents a first attempt to characterize the proteomic profile of leiomyomas after treatment with UPA, in order to identify dysregulated proteins correlated with the drug's mechanisms of action.

Through a combination of 2-DE and mass spectrometry, we identified 30 proteins dysregulated by the pharmacological treatment. Subsequent western blot analysis confirmed the altered expression of three of these proteins: HSPB1, PDIA3, and ACTG2.

Peroxiredoxin 6 (PDRX6), an enzyme involved in the reduction of water and alcohol, exerts its enzymatic activity on $\mathrm{H} 2 \mathrm{O} 2$, fatty acids and phospholipid hydroperoxides $(21,22)$.

In our study, PDRX6 was up-regulated (in treated leiomyoma samples) suggesting that its detoxifying function in cancer cells might bear some relation with the mechanisms of action of the drug.

SOD1, which contributes to the destruction of toxic free radicals $(23,24)$ activating the degradation of hydrogen peroxide, also appeared to be up-regulated in treated leiomyoma. Considering that SOD1, as well as PDRX6, are involved in the destruction of free radicals protecting the cell from oxidative stress.

APOA1 is involved in the mechanism of reverse transport of cholesterol from peripheral tissues back to the liver for excretion in the bile (25). Interestingly, it has been shown that APOA1 overexpression can improve abnormal lipid metabolism in non-alcoholic steatohepatitis (NASH). This protective effect is due to its ability to decrease the levels of reactive oxygen species and suppress COX-2-induced inflammation in hepatocytes $(26,27)$. In our study, this protein was down-regulated and this effect could bear some connection with the activity of the drug on leiomyoma cell.

HSPB1 is a molecular chaperone capable of preventing the aggregation of misfolded proteins, an event which is easily triggered/induced in a variety of different types of cancer cells, following treatment with Erastin, a ferroptosis-inducing agent $(28,29)$.

The phosphorylation of HSPB1 reduces the iron-mediated production of lipid reactive oxygen species, thus conferring cancer cells protection against ferroptosis $(30,31)$.

The disruption of HSPB1 expression following UPA treatment, suggests that there may be a correlation between production of lipid reactive oxygen species, ferroptosis, and drug treatment.

TAGLN is a cytoskeletal protein of the calponin family that has been shown/suggested to contribute to replicative senescence $(32,33)$. Downregulation of TAGLN in leiomyomas treated with UPA, induces the synthesis of reactive oxygen species, causing an increase of these reactive species inside the cell.
To our knowledge, this is the first study that applies proteomics to investigate the mechanisms underlying the effectiveness of the treatment of leiomyoma with ulipristal acetate. Using bioinformatic tools, we identified several proteins associated with oxidative stress, suggesting that the mechanisms of action of the drug may be related to its effect on oxidative stress The main limitation of the study is that it doesn't address the functional aspects of the mechanisms of action of UPA. Another limitation of the study is the lack of technical replicates of western blotting.

However, in terms of clinical application, our study offers the advantage of addressing directly the mechanisms involved not only in hormonal metabolisms but also in protein expression, with the aim of identifying new and more effective molecules.

We need to clarify that the aim of our study was to investigate the implication, in terms of oxidative stress, of using ulipristal acetate in leiomyoma from a biochemical point of view. We believe that our findings could direct further studies toward the research for new molecules (in addition to the ulipristal acetate, which has been currently removed from the market) with a specific target to reduce oxidative stress. The ulipristal acetate has been removed from market under EMA (European Medicines Agency) recommendation due to rare side effects to the liver.

In conclusion, by analyzing the leiomyoma tissue of patients treated with UPA and comparing their proteomic profiles with samples obtained from patients receiving no treatment, we found some markers of interest. Several proteins involved in oxidative stress were down- or up-regulated following UPA treatment. Since oxidative stress is critical in a variety of conditions, including cancer, the ability of UPA to modulate this event is highly promising. Therefore, we believe that additional studies would help better understand the role of UPA in the treatment of leiomyoma.

\section{Acknowledgements}

The authors would like to thank Dr Alessandra Knowles (Institute for Maternal and Child Health-IRCCS 'Burlo Garofolo', Trieste, Italy) and Dr Martina Bradaschia (Institute for Maternal and Child Health-IRCCS 'Burlo Garofolo', Trieste, Italy) for the English revision of the manuscript.

\section{Funding}

This research was funded by the Italian Ministry of Health (grant no. RC 27/17)-Institute for Maternal and Child Health IRCCS Burlo Garofolo, Trieste, Italy.

\section{Availability of data and materials}

All data generated or analyzed during this study are included in this published article.

\section{Authors' contributions}

BU, FS, FR, SB and GR conceived and designed the experiments. YCCDS, MA, BG, CF and EA performed the 
experiments. BU, DL, GDL, GS, GA and LM analyzed the data. BU, LM, FR, SB, FS and GR wrote the paper. All authors read and approved the final manuscript.

\section{Ethics approval and consent to participate}

All study procedures complied with the Declaration of Helsinki and were approved by the Institutional Review Board of the Institute for Maternal and Child Health-IRCCS 'Burlo Garofolo' (Trieste, Italy) (RC 27/2017). All patients signed a written informed consent form.

\section{Patient consent for publication}

Not applicable.

\section{Competing interests}

The authors declare that they have no competing interests.

\section{References}

1. Ura B, Monasta L, Arrigoni G, Licastro D, Di Lorenzo G Romano F, Gaita B, Scrimin F and Ricci G: Leiomyoma phosphoproteins involved in inhibition of oxidative stress and synthesis of reactive oxygen species. Int J Mol Med 44: 2329-2335, 2019.

2. Kim JJ and Sefton EC: The role of progesterone signaling in the pathogenesis of uterine leiomyoma. Mol Cell Endocrinol 358 223-231, 2012.

3. Haney AF: Clinical decision making regarding leiomyomata: What we need in the next millenium. Environ Health Perspect 108 (Suppl 5): S835-S839, 2000.

4. Ura B, Di Lorenzo G, Romano F, Monasta L, Mirenda G, Scrimin F and Ricci G: Interstitial fluid in gynecologic tumors and its possible application in the clinical practice. Int $\mathbf{J}$ Mol Sci 19: 4018, 2018

5. Ura B, Monasta L, Arrigoni G, Battisti I, Licastro D, D Lorenzo G, Romano F, Aloisio M, Peterlunger I, Stabile G, et al: Phosphoproteins involved in the inhibition of apoptosis and in cell survival in the leiomyoma. J Clin Med 8: 691, 2019.

6. Ura B, Scrimin F, Arrigoni G, Aloisio M, Monasta L and Ricci G Dysregulated chaperones associated with cell proliferation and negative apoptosis regulation in the uterine leiomyoma. Oncol Lett 15: 8005-8010, 2018.

7. Ura B, Scrimin F, Zanconati F, Arrigoni G, Monasta L, Romano A, Banco R, Zweyer M, Milani D and Ricci G: Two-dimensional gel electrophoresis analysis of the leiomyoma interstitial fluid reveals altered protein expression with a possible involvement in pathogenesis. Oncol Rep 33: 2219-2226, 2015.

8. Kashani BN, Centini G, Morelli SS, Weiss G and Petraglia F: Role of medical management for uterine leiomyomas. Best Pract Res Clin Obstet Gynaecol 34: 85-103, 2016

9. Shin SJ, Kim J, Lee S, Baek J, Lee JE, Cho C and Ha E: Ulipristal acetate induces cell cycle delay and remodeling of extracellular matrix. Int J Mol Med 42: 1857-1864, 2018.

10. Sohn GS, Cho S, Kim YM, Cho CH, Kim MR and Lee SR Working Group of Society of Uterine Leiomyoma: Current medical treatment of uterine fibroids. Obstet Gynecol Sci 61: 192-201, 2018

11. Bendifallah S, Brun JL and Fernandez $\mathrm{H}$ : Myomectomy for infertile women: The role of surgery. J Gynecol Obstet Biol Reprod (Paris) 40: 885-901, 2011 (In French).

12. Yun BS, Seong SJ, Cha DH, Kim JY, Kim ML, Shim JY and Park JE: Changes in proliferating and apoptotic markers of leiomyoma following treatment with a selective progesterone receptor modulator or gonadotropin-releasing hormone agonist. Eur J Obstet Gynecol Reprod Biol 191: 62-67, 2015.

13. Horak P, Mara M, Dundr P, Kubinova K, Kuzel D, Hudecek R and Chmel R: Effect of a selective progesterone receptor modulator on induction of apoptosis in uterine fibroids in vivo. Int J Endocrinol 2012: 436174, 2012.
14. Maruo T, Ohara N, Yoshida S, Nakabayashi K, Sasaki H, Xu Q, Chen W and Yamada H: Translational research with progesterone receptor modulator motivated by the use of levonorgestrel-releasing intrauterine system. Contraception 82: 435-441, 2010.

15. Ura B, Monasta L, Arrigoni G, Franchin C, Radillo O Peterlunger I, Ricci G and Scrimin F: A proteomic approach for the identification of biomarkers in endometrial cancer uterine aspirate. Oncotarget 8: 109536-109545, 2017.

16. Ura B, Scrimin F, Arrigoni G, Franchin C, Monasta L and Ricci G: A proteomic approach for the identification of up-regulated proteins involved in the metabolic process of the leiomyoma. Int J Mol Sci 17: 540, 2016

17. Eaton SL, Roche SL, Llavero Hurtado M, Oldknow KJ, Farquharson C, Gillingwater TH and Wishart TM: Total protein analysis as a reliable loading control for quantitative fluorescent Western blotting. PLoS One 8: e72457, 2013.

18. Welinder C and Ekblad L: Coomassie staining as loading control in western blot analysis. J Proteome Res 10: 1416-1419, 2011.

19. Small B, Millard CEF, Kisanga EP, Burman A, Anam A, Flannery C, Al-Hendy A and Whirledge S: The selective progesterone receptor modulator ulipristal acetate inhibits the activity of the glucocorticoid receptor. J Clin Endocrinol Metab 105: 716-734, 2020.

20. Sabry M and Al-Hendy A: Medical treatment of uterine leiomyoma. Reprod Sci 19: 339-353, 2012.

21. Chen JW, Dodia C, Feinstein SI, Jain MK and Fisher AB: 1-Cys peroxiredoxin, a bifunctional enzyme with glutathione peroxidase and phospholipase A2 activities. J Biol Chem 275: 28421-28427, 2000.

22. Kang SW, Baines IC and Rhee SG: Characterization of a mammalian peroxiredoxin that contains one conserved cysteine. J Biol Chem 273: 6303-6311, 1998.

23. Pizzino G, Irrera N, Cucinotta M, Pallio G, Mannino F, Arcoraci V, Squadrito F, Altavilla D and Bitto A: Oxidative stress: Harms and benefits for human health. Oxid Med Cell Longev 2017: 8416763, 2017.

24. Nocella C, Cammisotto V, Pigozzi F, Borrione P, Fossati C, D'Amico A, Cangemi R, Peruzzi M, Gobbi G, Ettorre E, et al: Impairment between oxidant and antioxidant systems: Short- and long-term implications for athletes' health. Nutrients 11: 1353, 2019.

25. Akerlöf E, Jörnvall H, Slotte $H$ and Pousette A: Identification of apolipoprotein A1 and immunoglobulin as components of a serum complex that mediates activation of human sperm motility. Biochemistry 30: 8986-8990, 1991

26. Mao J, Liu W and Wang Y: Apolipoprotein A-I expression suppresses COX-2 expression by reducing reactive oxygen species in hepatocytes. Biochem Biophys Res Commun 454: 359-363, 2014.

27. Tsai MH, Lin ZC, Liang CJ, Yen FL, Chiang YC and Lee CW: Eupafolin inhibits PGE2 production and COX2 expression in LPS-stimulated human dermal fibroblasts by blocking JNK/AP-1 and Nox2/p47(phox) pathway. Toxicol Appl Pharmacol 279: 240-251, 2014

28. Sun X, Ou Z, Xie M, Kang R, Fan Y, Niu X, Wang H, Cao L and Tang D: HSPB1 as a novel regulator of ferroptotic cancer cell death. Oncogene 34: 5617-5625, 2015.

29. Rogalla T, Ehrnsperger M, Preville X, Kotlyarov A, Lutsch G, Ducasse C, Paul C, Wieske M, Arrigo AP, Buchner J and Gaestel M: Regulation of Hsp27 oligomerization, chaperone function, and protective activity against oxidative stress/tumor necrosis factor alpha by phosphorylation. J Biol Chem 274: 18947-18956, 1999.

30. Collier MP, Alderson TR, de Villiers CP, Nicholls D, Gastall HY, Allison TM, Degiacomi MT, Jiang H, Mlynek G, Fürst DO, et al: HspB1 phosphorylation regulates its intramolecular dynamics and mechanosensitive molecular chaperone interaction with filamin C. Sci Adv 5: eaav8421, 2019.

31. Razinia Z, Mäkelä T, Ylänne J and Calderwood DA: Filamins in mechanosensing and signaling. Annu Rev Biophys 41: 227-246, 2012.

32. Yang L, Hong Q, Xu SG, Kuang XY, Di GH, Liu GY, Wu J, Shao ZM and Yu SJ: Downregulation of transgelin 2 promotes breast cancer metastasis by activating the reactive oxygen species/nuclear factor- $\kappa$ B signaling pathway. Mol Med Rep 20: 4045-4258, 2019.

33. Shapland C, Hsuan JJ, Totty NF and Lawson D: Purification and properties of transgelin: A transformation and shape change sensitive actin-gelling protein. J Cell Biol 121: 1065-1073, 1993. 